\title{
COMIDA, MEMÓRIA SOCIAL E O ENCONTRO DE GERAÇÕES: A RETOMADA DO SABER-FAZER DE UMA RECEITA DE FAMMÍLIA
}

Daniel Oliveira $^{1}$

Resumo: Este artigo propõe analisar os acontecimentos relacionados a necessidade de revisitar a receita de um bolinho crocante conhecido em uma região do estado do Piaú com mirrado. A demanda por fazê-lo surgiu em razão de uma antiga amiga da minha família, que estava distante há muitos anos, manifestar a vontade de voltar a sentir o sabor dele, pois era algo bastante significativo das suas lembranças de adolescência. O evento proporcionou um encontro intergeracional de algumas mulheres da família, com o propósito de retomar um saber-fazer que a passagem do tempo havia deslocado para o plano das incertezas. As observações e narrativas aqui apresentadas são utilizadas como dados etnográficos que colocam em evidência como vínculos familiares lidam com processos de transformações que atingem práticas culturais e, por consequência, afetam a memória social.

Palavras-chave: Comida; família; saber-fazer; memória social; Piauí-Br.

Abstract: This paper proposes to analyze the events related to the need to revisit the recipe for a crunchy cookie known in a region of the state of Piauí with mirrado. The demand for doing so came about because an old friend of my family, who had been away for many years, expressed the desire to taste him again, as it was something very significant in her teenage memories. The event provided an intergenerational meeting of some women in the family, with the purpose of resuming a know-how that the passage of time had shifted to the plane of uncertainty. The observations and narratives presented here are used as ethnographic data that highlight how family ties deal with transformation processes that affect cultural practices and, consequently, affect social memory.

Keywords: Food; Family; know-how; social memory; Piauí-Br.

\section{Introdução}

A culinária pode ser entendida como um elemento fundamental na transmissão de saberes e fazeres entre gerações que, geralmente, nesses processos chamam a atenção dos estudos o protagonismo das mulheres. O presente paper pretende abordar sobre uma “experiência-próxima" (GEERTZ, 1997) gerada de um fato ocorrido no âmbito da família, no

\footnotetext{
${ }^{1}$ Doutorando do Programa de Pós-graduação em Antropologia da Universidade Federal do Pará (PPGA/UFPA). E-mail: daniel_oliveira@outlook.com. ORCID: https://orcid.org/0000-0002-5703-1452. Uma versão deste trabalho foi apresentada no XI Encontro Regional de História da Associação Nacional de História - ANPUHPA, que foi realizado entre os dias 27 e 29 de junho de 2018 na Universidade Federal do Pará, em Belém/PA.
} 
caso a minha, que enquanto antropólogo percebi a possibilidade de conduzir um diálogo para a construção de uma análise antropológica ${ }^{2}$.

A época do evento foi em maio de 2018, percebi que um circuito de informações havia sido acionado em volta da necessidade de retomar uma receita de família, o que para mim foi bastante interessante para se pensar a relação entre o saber e o fazer. Para isso, algumas mulheres da família do meu grupo de descendência materna, representantes de três gerações com graus de parentescos variados, foram agenciadas para cumprir com o objetivo; umas acudindo com a oralidade da memória àquelas que poriam literalmente a mão na massa, fora aquelas que posicionadas como espectadoras da dinâmica daquele fluxo, representando as novas gerações. Ellen Woortmann argumenta que: A família, não se reproduz apenas biologicamente, nem reproduz apenas sua
força de trabalho. Ela se reproduz também simbolicamente, e uma das
dimensões dessa reprodução pode ser apreendida pelo modo de comer. O
gênero é também construído, no plano das representações, através da
percepção da comida, quem come o quê, quando, em quais circunstâncias.
Com isso pode-se afirmar que a comida "fala" da família, de homens e de
mulheres, tanto para o pesquisador que realiza uma 'leitura' consciente dos
hábitos alimentares, como para as próprias pessoas do grupo familiar - e
através deste, da sociedade. (2013, p.2)

Em relação ao antropólogo presente naquela situação de campo ${ }^{3}$, fui posicionado como observador marginalizado, ou seja, não pude me inserir ativamente no processo em razão de categorias como sexo, idade e competência não terem sido negociadas. Embora não me fosse permitido ajudar, isso não foi impedimento para que eu pudesse ficar ali por perto acompanhando aquela pequena coletividade de mulheres focadas na missão. Interessava a elas buscar rememorar o saber-fazer dos chamados mirrados, para agradar a visitante esperada. Nisso há de se pensar nas razões daquilo ter se tornado um desafio naquele momento, ou seja, por que a receita, ou parte dela, havia sido deslocada para o plano das incertezas?

Um argumento possível seria a de que, segundo o historiador francês Pierre Nora (1993), a dinâmica múltipla, globalizada e fragmentada das sociedades atuais, descontínua os

\footnotetext{
${ }^{2}$ Segundo Geertz (1997), os conceitos de experiência-próxima são aqueles de concepção nativa, isto é, que seu significado e uso são construídos no meio social e por sujeitos, com diferentes significados, dependendo do contexto ou sociedade. E o conceito de "experiência-distante" indica os conceitos que o etnógrafo ou demais cientistas utilizam para trazer à tona explicações sobre seus objetivos científicos, como por exemplo, memória, ritual, cultura e religião. Com as estruturas conceptuais definidas, pode-se então traduzir um acontecimento ou comportamento, ou seja, a partir da identificação de conceitos de significação nativa, o etnógrafo arrola-os a ideias teóricas, traduzindo-os transformando em palavras algo que foi observado.

${ }^{3}$ Define-se pelo conjunto de relações complexas que se estabelecem entre o observador e seus anfitriões. A situação de campo é uma configuração singular que depende dos parâmetros próprios ao campo, bem como da equação pessoal do pesquisador (LABURTHE-TOLRA, p. 426, 1997)
} 
processos de transmissão das memórias. Assim, dependendo do contexto, os lugares se tornam o meio de acesso à memória, porque não há mais outros meios de memória, pois com a dinâmica quente da história, transforma rapidamente toda memória social baseada nos costumes e tradições, que se tornam distantes do presente. Esses deslocamentos são estimulados pela crescente prevalência da ideologia individualista típica das sociedades modernas, especialmente valorada entre as classes médias-urbanas, assim, a fragmentação observada nos indivíduos se reflete na fragmentação da família (DUARTE, 1994, p. 32) ${ }^{4}$.

Para situar, a narrativa desse "lugar de memória" descortinou-se no Povoado Baixa Grande, uma pequena comunidade ${ }^{5}$ encravada à beira da BR 316, pertencente ao município de Monsenhor Gil, localizado na região do Médio Parnaíba no estado do Piauí. O povoado está a $10 \mathrm{~km}$ de distância da sede do município. A população geral é estimada em cerca de dez mil habitantes resguardando o ethos bucólico típico de localidade do interior. O lugar está ambientado em uma zona de cocais, rica em palmeiras das mais variadas espécies, entre elas: carnaúbas, babaçueiros, buritizeiros e tucunzeiros; essa composição vegetal compartilha espaço com uma grande diversidade de árvores frutíferas, entre as principais podemos encontrar cajueiros, mangueiras, umbuzeiros, goiabeiras, mamoeiros, pitombeiras, entre outras.

Pensando nisso, aquela paisagem etnográfica emoldurava para mim o que Nora chama de "lugar de memória", dado o seu potencial evocativo da identidade cultural de um grupo social, que naquele momento operava como que um laboratório de memória em que os sujeitos envolvidos pudessem recorrer para tornar o empreendimento eficaz.

A interação do homem com essa paisagem natural tem reflexos nas práticas alimentares tradicionais da localidade, como é o caso da cajuína que na época do caju é possível ser encontrada facilmente nas diversas chácaras familiares a produção artesanal em atividade. Inclusive o referido povoado se tornou um dos locus de pesquisa que fundamentaram o dossiê de registro da cajuína como patrimônio cultural do Brasil, inscrito no Livro dos Saberes do Instituto do Patrimônio Histórico e Artístico Nacional - Iphan, no ano

\footnotetext{
${ }^{4}$ Segundo Luiz Fernando Dias Duarte, a maior parte das características sociomorfológicas atribuídas aos efeitos da individualização na sociedade moderna é inseparável das características do modelo de família [...]: a primeira delas é certamente a da "fragmentação", a da redução das unidades sociais à sua forma mais "indivisível", fazendo com a própria "família nuclear" possa corresponder a uma espécie de indivíduo (indiviso) coletivo. (DUARTE, 1994, p. 32)

${ }^{5}$ Do ponto de vista metodológico os estudos com família e parentesco lançam um desafio ao pesquisador no que diz respeito ao locus da pesquisa. Para Martine Segalen, a pesquisa de campo no meio rural remota aos estudos clássicos da antropologia, onde o pesquisador pode realizar uma imersão mais vigorosa no contato com os sujeitos. Já no meio urbano, segundo ela, esta atitude não é sensata e/ou é bem mais complexa, uma vez que as pessoas estão espalhadas, as famílias desmembradas, as comunidades locais fragmentadas ou, até mesmo, não existem mais (ECKERT, 2001, p. 282).
} 
de 2014. A política de patrimonialização considerou relevante no processo de identificação a "Produção Tradicional e Práticas Socioculturais Associadas à Cajuína no Piaú'”, celebrando mais do que simplesmente a produção da bebida, levando em conta também como a cajuína simboliza a hospitalidade e os laços existentes entre as famílias produtoras (IPHAN, 2014)

$\mathrm{O}$ argumento elaborado para o registro explícita bem como parte das minhas memórias familiares foram construídas. Eu, como pertencente a uma família de produtores de cajuína, que para além de ser um espectador dos ciclos ano após ano dos processos produção ${ }^{6}$, sempre presenciei meu avô receber suas muitas visitas que ali chegavam e instantaneamente solicitava à minha avó, ou às filhas ou netas presentes, que oferecessem o café quentinho, acompanhado do doce de buriti e da cajuína gelada. Esse trio degustativo não poderia faltar nunca!

Ressalto ainda que mesmo sendo um membro pertencente ao grupo familiar, o meu lugar de fala é de um indivíduo criado na capital, que esporadicamente visitava a casa dos avós no período de férias. Que por isso não alcança toda a diversidade de termos êmicos, utilizados para classificar coisas e objetos, em especial aqui os da zona de alimentação, que vejo passar em meus frames de memória. Mas que estas são preenchidas pelas cores, cheiros e sabores da cajuína, do doce de buriti, do doce de caju, do azeite de coco babaçu, são muitas das narrativas possíveis de serem exploradas como a que trago aqui sobre os mirrados.

De fato, muitas outras práticas alimentares locais ainda não capitalizaram, ou talvez nem venham a adquirir, o mesmo vigor da cajuína frente aos conceitos-critérios para merecerem a atenção das políticas de patrimônio. Produzir patrimônio, por sua vez, refere-se a converter em patrimônio (ou construí-lo a partir de) determinados elementos preexistentes, selecionados entre outros que se excluem desse processo. (HERNÁNDEZ, 2005).

Segundo o antropólogo Jesús Hernández (2005) atualmente não existe aspecto da vida social que não seja tratado em termos de patrimônio. Mas há de se pensar que a ascensão de um bem cultural no cenário das políticas públicas de patrimônio cultural tem relação com a canalização de forças culturais, sociais, políticas e, também, econômicas interdependentes formuladas para sua produção.

\footnotetext{
${ }^{6}$ A cadeia produtiva é composta de etapas que exigem bastante precisão e minucia, como na separação do tanino provocada pela adição de gelatina em pó, que seria o primeiro processo de clarificação do sumo do caju espremido; na sequência vem a filtragem dele em filtros feitos de tecido que devem permanecer estáticos. Para adquirir a cor caramelizada, característica da cajuína, no Piauí o suco é engarrafado em garrafas de vidro tampadas se são levadas para serem cozinhadas em banho-maria, nesse processo há o risco de algumas garrafas explodirem dentro dos tachos ferventes. Portanto, é um ambiente um tanto hostil para crianças permanecerem por perto.
} 


\section{Lembrar de comer, comer para lembrar}

Após uma breve contextualização da ambientação do percurso etnográfico, importa agora situar as conversas que neste ensaio revelam os fluxos de memória que emergiram em ocasião da visita de uma amiga de longa data da minha família materna, que chegaria no fim do mês de maio de 2018.

As narrativas que se desenrolaram no referido evento serviram para observar que na tentativa de feitura dos mirrados, ocorreu um alinhamento entre categorias analíticas sobrepostas na distribuição do conhecimento ${ }^{7}$ de saberes alimentares tradicionais entre os entes da família, tais como: geração, gênero e territorialidade. Basicamente a autoridade para manipular a receita está no trabalho das mulheres, em especial, aquelas das gerações mais velhas que permaneceram no meio rural. Estas demonstravam maior competência na operacionalização tanto do saber quanto do fazer, por meio de técnicas que prescinde de espaços adequados entre a casa e o quintal, bem como os instrumentos materiais e os ingredientes necessários.

Como ponto inicial para essa reflexão se faz necessário apresentar o protagonista dessa narrativa, os mirrados. O que são eles? Para ajudar a entender trago aqui um breve relato oral da minha mãe, em que ela recorre às suas memórias de infância para nos apresentar um aporte descritivo sobre como esse bolinho feito da goma de mandioca é produzido:

O mirrado é um tipo de bolo que reporta a minha infância. Minha mãe quando fazia escolhia sempre um final de semana que era quando ela tinha um pouco mais de tempo. É um bolo feito de goma de mandioca bem fininha, no que era necessário esfregar bem a goma nas mãos e peneirar, hoje nos temos polvilho, daí era só acrescentar água, sal, óleo fervente e bastantes ovos, depois é só socar bem com as mãos para dá o ponto. Bem trabalhoso! Lembro bem que minha mãe acendia o forno a lenha ainda pela manhã, só à tardinha é que ficava na temperatura ideal. Tirava-se toda a brasa do forno, passava-se uma vassoura para garantir que não tinha mais brasa, daí era só colocar colheradas de massa em um saco feito de tecido com furo e desenhar as mirradas em forma de montanhas. A dança dos flandes ${ }^{8}$ dentro do forno era a parte mais difícil. Num certo tempo, o flande que estava na frente era colocado na parte de trás, o detrás vinha pra frente, tudo isso com a cara dentro forno bem quente. Dependendo da quantidade de massa ia noite adentro. $\mathrm{O}$ armazenamento era feito em lata de alumínio bem fechada e

\footnotetext{
${ }^{7}$ Na perspectiva de uma antropologia do conhecimento proposta por Frederik Barth (1987), cabe ao etnólogo analisar as manifestações culturais a partir da distribuição diferenciada de saberes entre os indivíduos que fazem parte de um grupo social. Assim, Barth se opõe aos modelos homogeneizantes de definição do conceito de cultura, que para ele seriam abstrações. Seu modo de proceder procura identificar os desenvolvimentos, desvios e dogmatismos de cada tradição de conhecimento, para descobrir os padrões de variação e, portanto, os processos subjacentes de inovação e estímulo do pensamento que operam nos mesmos.

${ }^{8}$ Como são chamadas as assadeiras para bolos fabricadas artesanalmente do aproveitamento das latas de querosene, que são utilizadas nos fornos artesanais que ainda são bastante comuns nos quintais da região.
} 
podia ser consumido em até três meses com a mesma qualidade. (Informação oral, Angelita Oliveira, 2018)

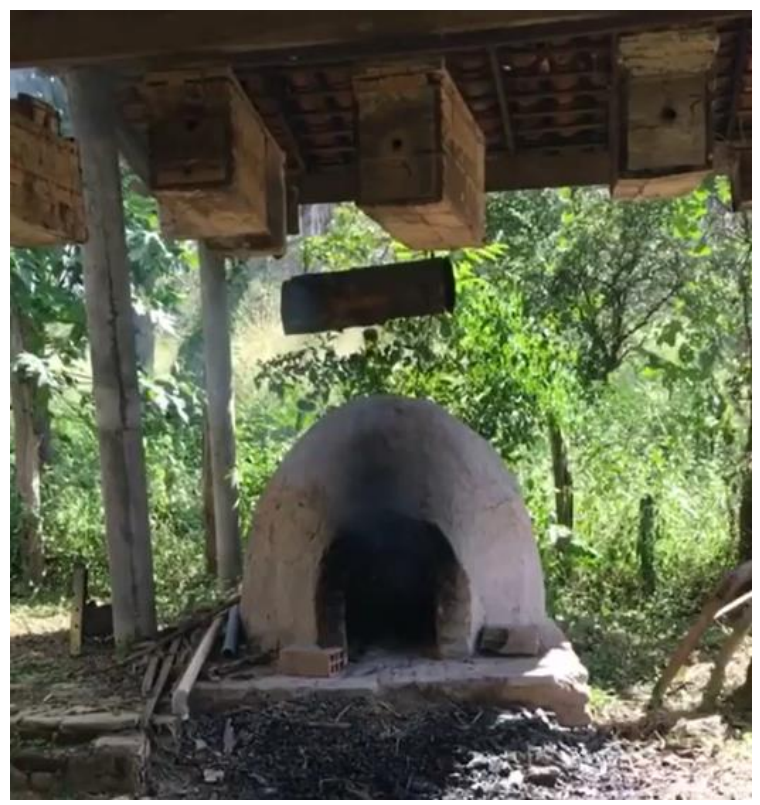

Figura 1. Aquecimento do forno de barro no quintal. Foto: Gabriela Rodrigues, 2018.

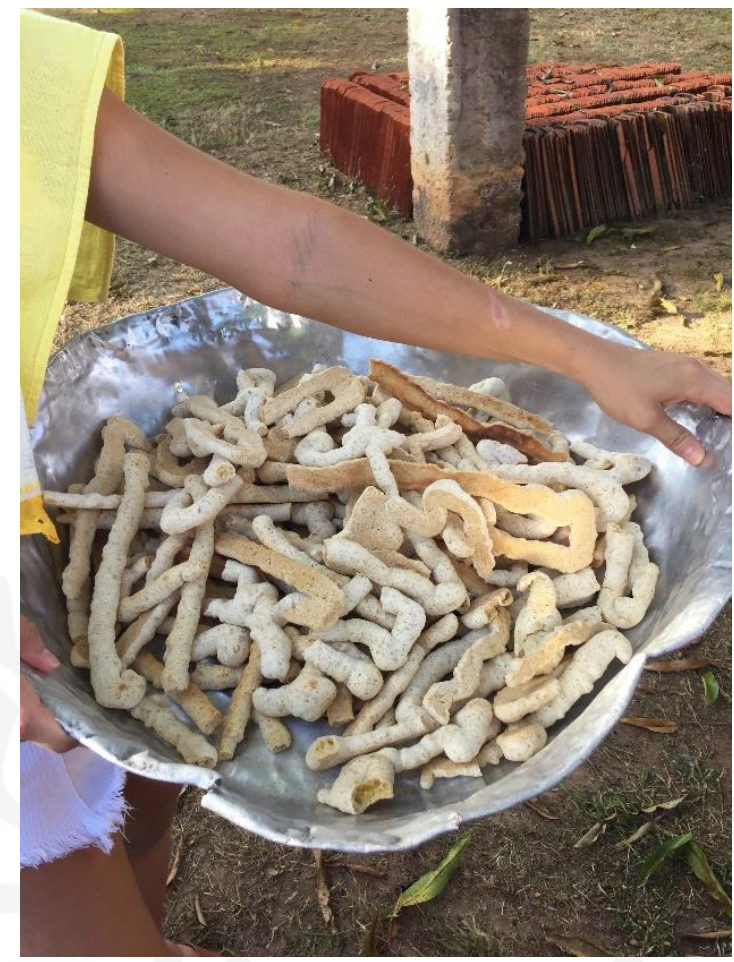

Figura 2. Mirrados prontos e à espera da visitante. Foto: Daniel Oliveira, 2018

Parece tratar-se aqui de uma narrativa de deslocamentos e aproximações geradas pelas experiências vividas nas dinâmicas da modernidade. A demanda para fazer os mirrados chegou lá da cidade do Recife através da rede social Facebook. Uma amiga de adolescência 
da minha mãe, filha de seu padrinho de batismo, enviou uma mensagem determinada a realizar uma viagem de imersão às suas origens. Passados mais 40 anos sem ir ao Piauí, ela iria reencontrar tantos os seus familiares, quanto os da minha família. Para que isso fosse mais fiel ao projeto dela de reencontro, o campo gastronômico deveria ser acionado e composto por diversos elementos, entre os pedidos feitos por ela estavam o capote com arroz, o doce de buriti, e claro, os mirrados. ${ }^{9}$ No que diz a Dona Angelita, sua amiga enfatizou bastante entre as possibilidades culinárias a vontade de voltar a comer os mirrados, no que diz a Dona Angelita:

O motivo do resgate da receita do mirrado é que na época tinha uma amiga, que quando completou 15 anos foi morar fora e nunca mais tinha aparecido e agora ela resolveu voltar para rever os amigos e amigas. E era no que ela falava, era nesse mirrado, nesse bolo e pediu que se tivesse a oportunidade de fazer, de lembrar da receita que fizesse e assim foi feito. Aí ela veio fazer todo o processo que eu já falei antes. Ela ficou dizendo que era para reportar a infância dela (Informação oral, Angelita Oliveira, 2018).

$\mathrm{Na}$ semana anterior à visitação, minha mãe passou a articular como faria para corresponder às expectativas da amiga, em especial, a produção dos mirrados caseiros. Assim, foi tomando forma a movimentação encabeçada por minha mãe que se antecipou em convocar sua irmã mais nova para ajudá-la a pôr em prática o projeto. Um detalhe é que esta foi a única das cinco irmãs que não foi morar na capital ${ }^{10}$, talvez por isso tenha conservado os elementos do saber-fazer com mais desenvoltura. Mas também é importante ressaltar, que foram as irmãs mais velhas que jogaram a responsabilidade para a mais nova, talvez como estratégia para escapar da etapa mais dura do trabalho que é misturar a pesada massa.

\footnotetext{
${ }^{9}$ Pode-se considerar que a atual explosão de patrimônio é uma manifestação da modernidade. Ela se faz presente no aumento da sensibilidade estética, por meio de signos e dos objetos e artefatos que possuem um toque de antiguidade, dos velhos lugares e edifícios, do artesanato e também, [...], dos alimentos tradicionais, as velhas receitas, pelas "cozinhas das avós" (ESTEVEZ apud HERNÁNDEZ, 2005)

${ }^{10}$ Para as filhas e filhos de meus avós que foram morar na capital, ou mesmo aqueles que mudaram de residência, mas permaneceram na comunidade, o sentimento de pertencimento ao lar dos pais mantém-se ativo em seus discursos. Por muitas vezes eu ouvia da minha mãe, tias e tios, se referirem à casa dos pais como "lá em casa", que hoje posso interpretar como um recurso discursivo que revigoraria seus laços de afetividade com aquele território, o que talvez exprimisse uma espécie de bilocalidade. Segundo a antropóloga Emília Pietrafesa de Godoi (2018), citando Marshall Sahlins, "a própria reprodução de grupos domésticos e residenciais, que até podem coincidir com unidades territoriais, exige que alguns de seus membros migrem, sem com isso significar perda do território; ao contrário, suas vidas passam a ser multilocais e seus territórios de vida e de trabalho descontínuos".
} 


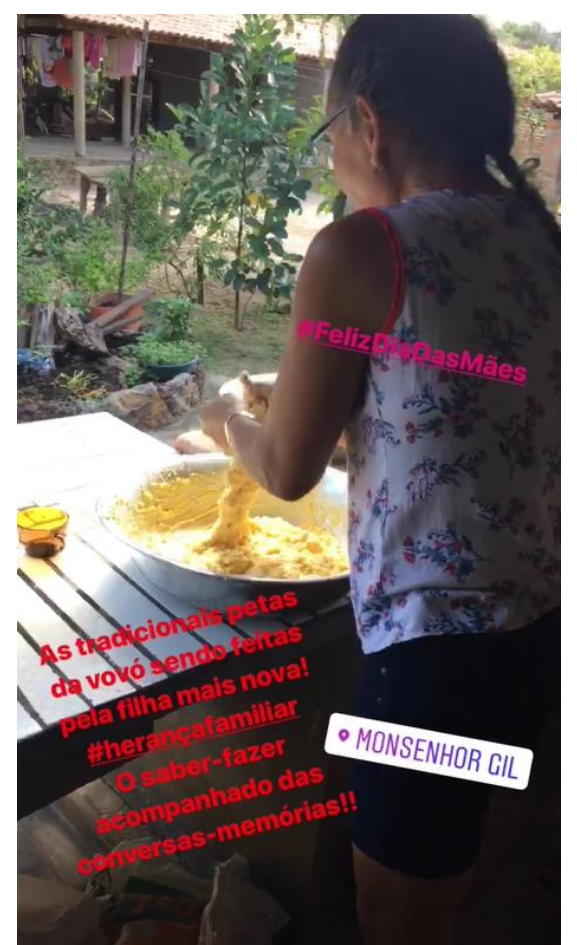

Figura 3. A mais nova das irmãs misturando a massa. Fonte: Gabriela Rodrigues, 2018

Na véspera do Dia das Mães do ano de 2018, a casa dos meus avôs estava cheia em razão da data comemorativa que todos os anos promove o encontro das gerações. Foi nesse cenário que minha mãe aproveitou o momento com a intenção de contar com toda a ajuda possível da família, para encarar aquele desafio de produzir os mirrados para amiga que chegaria ao transcorrer daquela semana que se iniciava.

$\mathrm{Na}$ ideia de que os alimentos são não apenas comidos, mas também pensados (WOORTMANN, 2013), minha mãe então ficou muita aflita, pois sondando com as irmãs e sua mãe, nenhuma delas recordavam de detalhes que seria, importantes na preparação da receita. A irmã mais nova, minha tia Izinha (49 anos), disse que lembrava dos ingredientes, de como fazer, mas não lembrava a quantidade exata de cada um dos ingredientes. Foi a mesma dificuldade demonstrada pela minha avó Luiza (83 anos).

Na minha infância e adolescência quando visitava meus avós em períodos de férias escolares ou mesmo feriados prolongados, eu sempre observava minha avó preparando os tais mirrados. No entanto, naquele momento crítico já havia um recuo de tempo de mais ou menos uma década que ela não os fazia mais ${ }^{11}$. Por isso, naquele instante a imagem dos

\footnotetext{
${ }^{11}$ Eu lembro-me bem que minha avó armazenava os mirrados em grandes latas reaproveitadas das margarinas de $20 \mathrm{~kg}$. Enquanto depósitos para guardar os mais variados mantimentos, estas ficavam trancadas na dispensa junto com os outros bens do cotidiano alimentar da família. Essa medida seria uma forma de administrar o consumo e assim garantir uma melhor distribuição dos alimentos, em um espaço de tempo planejado, em razão de uma família tão numerosa. As mulheres ocupam uma posição fundamental na alimentação da família por vários
} 
mirrados prontos ficou obnubilada, já que a matriarca da família demonstrou insegurança e, assim, assumir a responsabilidade de fornecer informações que talvez pudessem comprometela no resultado final, especialmente caso desse errado. A partir desse impasse, as irmãs se dirigiram para a casa do irmão que fica ao lado esquerdo, na esperança de que a cunhada pudesse resolver aquele dilema, o que não se realizou. Assim se deslocaram à moradia do lado direito, onde mora uma senhora amiga de longa data de meu avô, e também não obtiveram êxito. A breve jornada teve seu fim quando atravessaram a BR na direção da casa do irmão do meu avô. Foi a esposa dele que finalmente desvendou o mistério sobre a quantidade exata dos ingredientes necessários para o preparo da massa.

Ocorreu que para alcançar uma chave de solução que garantisse o sucesso da receita foi possível acessar uma rede de comunicação que é característica da tradicionalidade de um conhecimento, ora transmitido pela oralidade de geração para geração. Mesmo com a internet (via rádio) já presente naquela região, em nenhum momento se cogitou realizar uma googlada ${ }^{12}$ para resolver a problema, o que investe confiança no saber-fazer que se mantem resistente, pois as informações são de longa data obtidas por meio da atividade prática, baseadas na observação e na experiência.

Ao comentar sobre todo aquele episódio, que já se incorporou à memória dos atores envolvidos no que diz respeito aos mirrados, minha mãe lembra de como foi exaustivo todo o trabalho, além disso ela ponderou uma distinção geracional ao atribuir à sua mãe a maestria pelos muitos anos em que dedicou-se ao preparo do bolinho:

Muitos anos se passaram e agora por esses dias me vi tentando fazer minha mãe, hoje com 78 anos, lembrar da receita. Foi muito difícil, porque ela não lembrava mais. Eu e uma de minhas irmãs, juntamente com minha filha, tivemos que ir até a casa de uma tia minha que mora perto, para ver se ela lembrava. E ela não lembrava totalmente, mas tinha uma noção de como seria. E não é que deu certo! Só que eu não tenho a mesma garra de minha mãe em relação à confecção do tal bolo. Foi só uma vez e espero que tão cedo eu não volte a fazer aquele bolo, porque é muito difícil de fazer! (Informação oral, Angelita Oliveira, 2018)

motivos. Elas controlam, se não o orçamento doméstico, pelo menos as compras de alimentos, seu processamento, socializam os filhos para aceitá-los e distribuem a comida entre os componentes da família. Mais importante ainda, é que as mulheres têm maior acesso do que os homens a informações acerca da alimentação, provenientes de várias fontes e de programas diversos de orientação. As mulheres são mediadoras entre universos nos quais predominam regras alimentares diversificadas e podem ser agentes transformadores de hábitos alimentares (ROMANELLI, 2006, p.337).

${ }^{12}$ Neologismo que significa realizar uma pesquisa na Internet através do mais popular site de busca do mundo, o Google. 
Apesar da retórica pessimista ameaçar a efetivação da prática, a experiência demonstrou que em um momento crítico e inesperado, a memória pode ser acionada para surtir eficácia no tempo presente. Outro fato importante é que essa atualização do passado, também permitiu o encontro de gerações mais novas com práticas alimentares realizadas em outros tempos pelo grupo familiar.

\section{As controvérsias do tempo}

No meio disso destaque para a experiência afetiva vivida pela minha irmã, na época com 23 anos. Ela é uma apreciadora inveterada da culinária piauiense, preferência essa aguçada ainda mais a partir 2013, quando foi morar na cidade do Rio de Janeiro. O choque cultural mais significativo da nova vida foi sentido na alimentação, pois o seu paladar não se curvou ao sabor da comida carioca.

Ao comentar comigo o ponto de vista dela sobre os acontecimentos desencadeados pela feitura do mirrados, ela começa por expressar o ímpeto da territorialidade que enraizou seus hábitos alimentares:

O anúncio da chegada à cidade de uma amiga da minha mãe a quem ela não via há algumas décadas trouxe consigo pedidos inusitados. Daqueles que só quem é piauiense e fica algum tempo sem vir ao estado entende. A culinária daqui é inigualável, tanto aquela que podemos encontrar em outros estados, mas sem o mesmo sabor como criações únicas de nomes próprios e passadas de geração a geração. Pois mesmo morando em outra cidade do Nordeste, a tal amiga não esquecia sabores só experimentados aqui, que agora teriam, além do sabor, um gosto especial, capaz de remetê-la ao passado (Informação oral, Gabriela Rodrigues, 2018)

De modo geral, a construção dessa narrativa sobre as reações causadas pela amiga que iria chegar, demonstra uma perspectiva pela qual seria como se minha irmã reconhecesse e compartilhasse com a visitante a mesma melancolia típica de quem está distância de sua terra natal.

Foi por esse apreço a cozinha regional que ela decidiu acompanhar de perto todo o processo de feitura dos mirrados. Na classificação daquele encontro de gerações, a minha irmã era representava as novas gerações da família, mas havia também presentes crianças filhas de nossas primas que seriam da quarta geração.

Embora tenha visitado a casa dos nossos avós durante toda a vida, minha irmã não chegou a vivenciar muitas das práticas tradicionais dos modos de vida rurais, devido muitas delas terem ficado cada vez mais escassas de acontecer com o tempo. Portanto, a feitura dos 
mirrados foi uma oportunidade dela ter contato com a dinâmica de um saber-fazer que não fizera parte de sua trajetória de vida, em razão do modo de vida urbano que dominou a sua visão de mundo, bastante estimulado pela ênfase ao desenvolvimento do conhecimento formal em detrimento dos saberes do campo.

Ao discorrer sobre o assunto ela parece formular para si a invenção de uma tradição, que como diz Hobsbawn e Ranger (1997) ${ }^{13}$ servem para reforçar a coesão de grupo, no caso aqui o fomento de vínculos familiares. Vejamos o que ela nos diz:

$\mathrm{Na}$ lista, alguns pratos relativamente fáceis, mas um em especial chamou-me a atenção: teria que ser feito, minha mãe defendeu logo a necessidade da criação caseira como ela via minha avó fazendo. E essa experiência me possibilitou também observar algo novo dentro daquilo que é considerado antigo e tradicional. O dia escolhido foi o dia das mães, fomos todos pra casa da vó acreditando que ela saberia ensinar, mas confiando na habilidade e memória da tia mais nova que mais teve a vida parecida com minha vó. Percebo que até agora não falei o nome do tal negócio, talvez por não fazer tanta diferença na sua definição: mirrado. Eu, particularmente nunca tinha ouvido falar, mas é parecido com o que conhecemos como peta ou com o famoso biscoito globo do meu amado Rio. Pois bem, minha avó já não se lembrava como fazia, minha tia não tinha certeza quanto a quantidade de água, óleo e goma de tapioca - a de ovo só se sabe no olho na hora de fazer uma coisa já estava sendo feita, colocar pau do forno, aquele que parece uma oca, tão fofinho que a simples imagem da fumaça saindo de dentro daquilo traz uma sensação única. A mulher do meu tio também não se lembrava, "ah, a dona Francisca, a vizinha do lado, com certeza sabe" não a dona Francisca também já havia esquecido o segredo do tal mirrado. Outros nomes iam surgindo e as tentativas mais uma vez frustradas. Mas como ninguém se lembra da proporção desses ingredientes s gente? Minha mãe já ansiosa, sem tem algo com o qual ela gosta de agradar, esse algo é comida, o prazer dela em ver alguém gostando do que come é imenso. E uma amiga que queria tanto então... minha tia fala com minha vó e decidem então, juntas, confiar no achismo, 2 pra 2 pra 4, "acho que é mamãe" várias gerações ao redor, a filhinha da minha prima chegou até a provar com o dedo, gostando daquilo que colocara na boca mas certamente sem saber o que aquilo representava. Será que ela também, no futuro, irá querer sentir esse sabor de quando tinha seus primeiros anos de vida? Agora pensei que preciso confirmar a receita, talvez eu que terei que dizer pra ela como se faz o mirrado no futuro. Minha tia e mãe com as mãos na massa sob os olhares atentos de minha vó e minhas várias idas ao mercadinho da frente comprar o que ainda faltava - aos ovos que deveriam ser caipiras, teve que ser acrescentado ovos normais pois "são muitos ovos" elas disseram. Massa pronta, hora de levar ao forno, mas primeiro se coloca dentro de um saco plástico com um dos cantos furados pra possibilitar o desenho da massa na forma. E assim, entre várias fornadas, várias visitas e provas de filhos e netos, uma queda da minha tia, o mirrado foi virando realidade. A cada croc da sua mordida a confirmação de que é

\footnotetext{
${ }^{13}$ Uma "tradição inventada" é um conjunto de práticas, normalmente reguladas por regras tácita ou abertamente aceitas [...], de natureza ritual ou simbólica, [que] visam inculcar certos valores e normas de comportamento através da repetição, o que implica, automaticamente, uma continuidade em relação ao passado. (HOBSBAWN; RANGER, 1997, p. 9). Hobsbawn e Ranger (1997) distinguem as invenções políticas, de natureza "oficial" (festas cívicas, heróis nacionais, bandeiras e hinos) das invenções sociais, geradas por grupos sociais sem uma organização formal ou sem um objetivo político determinado.
} 
algo que não se esquece com o passar dos anos - mesmo que a receita exata sim (risos) - minha mãe fez questão de repetir: "isso não se encontra em padaria não...” não mesmo. (Informação Oral, Gabriela Rodrigues, 2018)

Diante do que foi relatado, o evento mostrou-se eficaz para a preparação dos mirrados, mas que também do ponto de vista daquele contexto cultural prestou atualizações de uma tradição por meio da convocação de referências ao passado. Nesses processos há de considerar que a construção social de uma realidade é, ao mesmo tempo, a construção dos sujeitos que a vivenciam. Ao discorrer sobre a categoria de patrimônios, o antropólogo Reginaldo Gonçalves (2002) nos chama atenção para uma característica fundamental que consiste em sua capacidade de "nos inventar". Com as novas gerações, geram novas relações sociais, daí o encontro entre diferentes membros, de várias gerações, emergem também novas formas de autoconsciência e autopercepção em todos os envolvidos.

Em uma crítica à antropologia da memória David Berliner (2005) argumenta que a "memória", como é usada pelos antropólogos, gradualmente se tornou um rótulo vago e confuso. O problema decorre, segundo o autor, em razão da expansão conceitual do conceito de memória se confundir muitas das vezes com a noção de cultura e sua reprodução. Assim, ele considera que é necessário fazer distinções terminológicas bem definidas. Portanto, caberia aos antropólogos compreender como as pessoas lembram e esquecem do passado.

Ao que parece, o meu grupo familiar recorreu à memória como mecanismo de reprodução cultural, mas não do passado em sua totalidade, o que ocorreu foi a construção do novo, do tempo presente, que ocorreu por meio do encontro de membros do grupo social para realizar ajustamentos aos problemas sentidos e vividos, ocasionado pela demanda da receita. Já a visitante, a memória teriam gerado nela uma expectativa de remetê-la a lembranças de outra época de sua vida.

No entanto, passados dois anos eu entrei em contato com a Valquíria (60 anos), para que ela pudesse me falar um pouco sobre o seu ponto de vista sobre aquele acontecimento e para minha surpresa ela declarou-me que não ficou satisfeita com o resultado, pois não era o mesmo sabor que ela lembrava. Vejamos como ela descreve a sua reação:

Depois de mais de 40 anos sem pisar os pés no Piauí, uma das primeiras comidas que lembrei foram daqueles bolinhos, pois me remetiam a minha adolescência. Quando íamos pra fazenda, dos seus avós, eram feitas fornadas, forno a lenha, desses bolinhos. Portanto, lembro do cheiro e sabor. Saímos da fazenda levando um vasilhame de alumínio lotado dos bolinhos! Quando falei com sua mãe, que ía ao Piauí, logo voltei ao passado, e lembrei-me dos bolinhos, pois os mesmos, a época que passamos juntas! Daí eu ter pedido para que os bolinhos fossem feitos. Queria lembrar do sabor 
daquela época! No momento que eu comi foi meio frustrante, não tinha o mesmo sabor! (Informação oral, Valquíria Pontes, 2020)

Sob esse ângulo dos fatos, mas do que cessar a questão, somos levados a inquirir algumas controvérsias. Partindo da premissa do que pode ser lembrado também pode ser esquecido, será que o sabor dos mirrados não teria se dissipado de sua memória? De certo que, trata-se de uma pergunta retórica dado que, ao seu modo, a Valquíria confrontou duas experiências por ela vivida pertencentes a dois tempos diferentes: o cronológico (khronos) e o social (kairos); que tudo indica, foram colocados como equivalentes na intenção do momento oportuno trazer de volta o momento do tempo sequencial.

\section{Considerações finais}

O desfecho da narrativa ilustra bastante como a noção de memória é um campo com muitas possibilidades de interpretação, que por isso lança um desafio aos pesquisadores ao tratar de questões relacionadas às subjetividades dos atores sociais que operam no encontro do tempo cronológico com o tempo social. Como vimos, no presente presente, um grupo de mulheres da mesma família se reuniu entorno de uma missão: atender um pedido de uma velha amiga pautada em sua memória-lembrança de uma experiência degustativa guardada há mais de 40 anos.

Esse episódio instigou-me a realizar uma análise antropológica dos fatos que observei in loco sobre a feitura dos mirrados. Naquele dia eu vi, ouvi e inclusive senti, não só o forte calor do forno de barro que assaria os bolinhos, mas também quando minha tia arrebatou-me o saco com a massa do bolinho dentro, quando eu estava me atrevendo em tentar desenhar em uma das assadeiras alguma outra forma que fugia do formato padrão. Lembro muito bem que era o mesmo utilizado por minha avó, e que minha tia fazia questão de manter igual. 


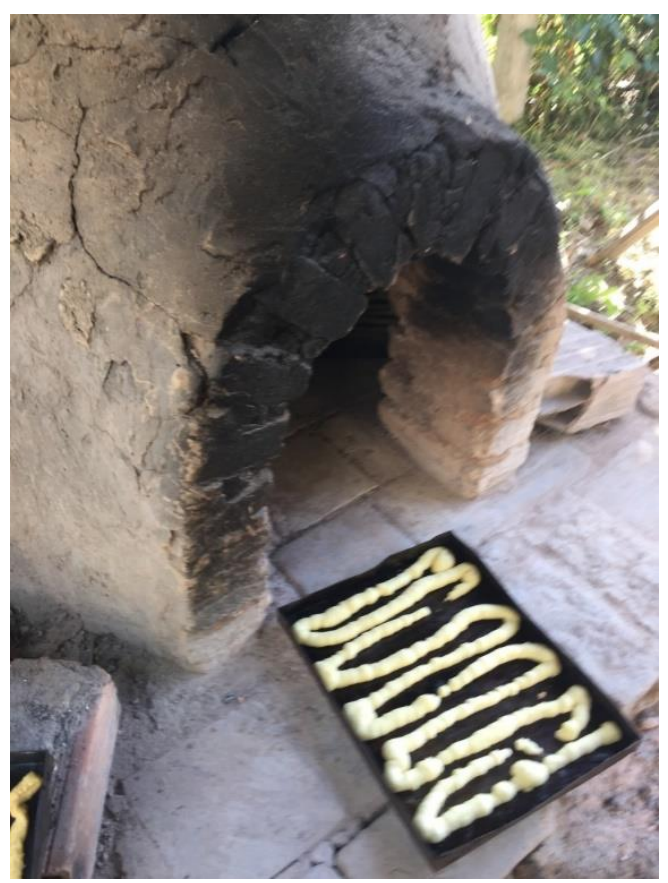

Figura 4. O formato dos mirrados. Foto: Daniel Oliveira, 2018.

E claro, também senti o sabor dos mirrados, com a crocância sonora caraterística de quando mordermos um pedaço. Francamente, eu não sei ao certo se não fui muito atento às sensações que eu tivera quando comia na época em que minha avó ainda os fazia, mas ao contrário da opinião da visitante, eu considerei que no geral o mirrado revisitado tinha o mesmo sabor.

Portanto, ainda que a abordagem tratando de um fato orquestrado por um pequeno grupo de mulheres da minha família, suas posições dentro dessa estrutura são representativas das gerações, enquanto categoria sociológica, que em contato criaram uma dinâmica intergeracional capaz de potencializar a circulação de conhecimentos relacionados a saberes e fazeres, que para algumas fez parte de toda a vida já para outras estavam tendo contato pela primeira vez. Em sumo, esse padrão de transmissão é a engrenagem dos patrimônios culturais, sejam eles reconhecidos ou não pelas políticas patrimônios das sociedades nacionaismodernas.

\section{Referências bibliográficas}

BARTH, Frederik. Cosmologies in the making. A generative approach to cultural variation in inner New Guinea. Cambridge. Cambridge University Press, 1987. 
BERLINER, David. Social Thought \& Commentary: The Abuses of Memory: Reflections on the Memory Boom in Anthropology In. Anthropological Quarterly, Vol 78, N. 1, 2005, pp. 197-211.

DUARTE, Luiz Fernando Dias. Horizontes do indivíduo e da ética no crepúsculo da família. In: RIBEIRO, I.; RIBEIRO, A. C. I. A família em processos contemporâneos: inovações culturais na sociedade brasileira. São Paulo: Loyla, 1994.

ECKERT, Cornelia et al. Qual é a Antropologia do Parentesco e da Família no século XXI? Um diálogo franco e brasileiro com Martine Segalen. Horizontes Antropológicos. Porto Alegte: PPGAS/UFRGS, ano 7, n. 16, 2001.

GEERTZ, Clifford. Do ponto de vista dos nativos: a natureza do entendimento antropológico. In: $O$ saber local: novos ensaios em antropologia interpretativa. Petropolis, RJ: Vozes,1997.

GODOI, Emília Pietrafesa de, and AGUIAR, Vilênia V. Porto. Mulheres e territórios vividos em contextos rurais: um olhar sobre a política de desenvolvimento territorial. In: Cadernos Pagu, no 52, 2018.

GONÇALVES, J. R. S. A retórica da perda: os discursos do Patrimônio Cultural no Brasil. Rio de Janeiro: UFRJ, 2002.

HERNÁNDEZ, Jesús C. Patrimônio e globalização: o caso das culturas alimentares. In CANESQUI, A. M., and GARCIA, R.W. D., (orgs). Antropologia e nutrição: um diálogo possível [online]. Rio de Janeiro: Editroa Fio Cruz, 2005.

HOBSBAWM, E.; RANGER, T. (Org.). A invenção das tradições. Rio de Janeiro: Paz e Terra, 1997.

IPHAN. Dossiê - Produção artesanal e práticas socioculturais associadas à cajuína no Piauí, 2014. Disponível em: http://portal.iphan.gov.br/uploads/ckfinder/arquivos/Dossie_cajuina_piaui.pdf

LABURTHE-TOLRA, Phelippe; WARNIER, Jean-Pierre. Etnologia - Antropologia. Petrópolis: Vozes, 1997.

NORA, Pierre. Entre Memória e História: a problemática dos lugares. In: Projeto História: Revista de Estudos Pós-Graduados em História e do Departamento de História da PUC-SP. São Paulo: PUC-SP, 1981.

ROMANELLI, G. O significado da alimentação na família: uma visão antropológica. Medicina (Ribeirão Preto), p. 333-339, 2006.

VELHO, Gilberto. Memória, identidade e projeto. Projeto e metamorfose: antropologia das sociedades complexas. Rio de Janeiro: Jorge Zahar, 1994.

WOORTMANN, Ellen. A comida como linguagem. Habitus. Goiânia, v. 11, n.1, p. 5-17, jan./jun. 2013. 